\title{
Schopenhauer como teórico de la virtud
}

\author{
Schopenhauer as theoretical of the virtue
}

\author{
Luciana Samamé \\ Doutoranda em Filosofia pela Universidad Nacional de Córdoba (Córdoba-Argentina). \\ E-mail:lucsamame@yahoo.com.ar
}

\begin{abstract}
Resumen: En este trabajo me propongo mostrar en qué medida puede Schopenhauer ser reconocido como un teórico de la virtud, y contribuir en tal sentido, a las discusiones contemporáneas. Con arreglo a ello, se explorarán aquí dos grandes líneas de análisis: por un lado, una que permita evidenciar que las críticas que el autor de El mundo como voluntad y representación lanza contra la ética kantiana, tanto anticipan como motivan, las críticas que le serán asimismo efectuadas en el S. XX, favoreciendo el resurgimiento de las éticas de la virtud; por otro lado, se intentarán poner de manifiesto los elementos principales de la teoría ética schopenhaueriana, por los que admitiría ser considerada propiamente en términos de una ética de la virtud. Finalmente, se examinará un argumento de peso por el que esta filiación que pretendemos establecer aquí, podría verse lesionada; ante lo cual se ensayará una solución plausible.
\end{abstract}

Palabras clave: Schopenhauer; Ética; Virtud.

\begin{abstract}
In this paper I aim to show to what extent Schopenhauer can be regarded as a virtue theorist, and in this respect can contribute to contemporary discussions. Two broad outlines of examination will be explored here in relation to this: on the one hand, we will try to exhibit that Schopenhauer's criticisms to Kantian Ethics, either to anticipate or motivate contemporary criticisms of the latter, helping to prompt the renewal of virtue ethics; on the other hand, we will try to show those aspects through which Schopenhauer's ethical theory can be considered properly, in terms of a virtue ethics. Lastly, a powerful objection will be examined regarding the idea we intend to defend here, i.e., that of the affiliation between Schopenhauer and virtue ethics; to which we will try to offer a plausible solution.
\end{abstract}

Keywords: Schopenhauer; Ethics; Virtue.

\section{Consideraciones preliminares}

En este trabajo nos proponemos defender la proposición conforme con la cual, la ética schopenhaueriana puede ser vista, con todo derecho, como una especie de ética de la virtud, y que incluso es posible emparentar algunos de sus elementos característicos con la de aquellos propios de la rehabilitación contemporánea de este tipo de teoría, la cual se presenta como alternativa al deontologismo y el consecuencialismo respectivamente, las dos corrientes dominantes en filosofía moral desde el S. XVIII en adelante. Creemos, así, que es viable establecer una filiación entre Schopenhauer y las corrientes enmarcadas en las denominadas éticas de la virtud, desde un doble frente: por un lado, a raíz de sus críticas a la ética kantiana; por el otro, a través de su concepción de la teoría ética y de la clase de nociones centrales que emplea, como las de carácter y virtud. Estas dos grandes líneas argumentativas, dada la cantidad e importancia de componentes que involucran, no 
podrán ser presentadas aquí más que en forma programática, a la espera de una exploración más detallada y completa en futuros trabajos. A los presentes propósitos, dividiremos nuestra exposición en tres grandes secciones: en la primera enunciaremos algunas de las críticas que Schopenhauer lanza contra Kant; en la segunda, procuraremos resaltar los elementos de la ética schopenhauriana por los cuales podría ser considerada una ética de la virtud; en la tercera, plantearemos una objeción ante dicha posibilidad, y asimismo también, la tentativa por resolverla.

\section{Las críticas de Schopenhauer a Kant: anticipo de las críticas contemporáneas}

Schopenhauer desmarca tajantemente su filosofía moral de la perspectiva kantiana, por lo que llega a sostener que la misma, en sus puntos esenciales, se opone diametralmente a la del filósofo de Könnigsberg ${ }^{1}$. Es interesante advertir que gran parte de las críticas que el primero avanza contra este último, anticipan, en efecto, las críticas que en el siglo XX propiciarán el resurgimiento de las éticas de la virtud. En esta dirección, Cartwright asevera que Schopenhauer podría ser considerado, con toda razón, como uno de los antecesores filosóficos de la actual reevaluación de la "fillosofía moral moderna"². O en palabras de Atwell: Schopenhauer enumera prácticamente la mayoría de las críticas perpetradas a la ética kantiana en los últimos doscientos años ${ }^{3}$. Mencionamos a continuación algunas de las objeciones más resonantes que antepone a Kant, principalmente en su ensayo El fundamento de la moral, y que encontrarán eco más tarde en teóricos de la virtud del S. XX, a saber: 1) que una concepción legalista de la ética deriva del pensamiento moral judeo-cristiano, de modo que nociones tales como las de "ley moral" y "obligación" sólo tienen sentido a la luz de un legislador dispensador de premios y castigos; 2) que los imperativos no pueden ser nunca categóricos, sino siempre hipotéticos; 3) que el incentivo moral no se identifica en absoluto con el puro respeto por la ley moral; 4) que Kant introduce de manera confusa la noción de "bien supremo"; etc.

Aquí nos detendremos en un aspecto particular de este criticismo: en la recusación schopenhaueriana de las bases no-empíricas sobre las que se asienta la ética kantiana. En vinculación con ello, son dos los aspectos, conexos entre sí, que le son objetados: por un lado, su carácter prescriptivo; por el otro, su pretensión de legitimarse en forma pura y a priori, sin considerar la naturaleza real o empírica de los seres humanos. Con relación al prescriptivismo, Schopenhauer fundamenta su rechazo, básicamente, en dos razones. La primera de ellas se sustenta por la tesis de la invariabilidad del carácter humano: en su opinión, dado que el carácter moral de un agente es innato y

\footnotetext{
${ }^{1}$ Cf. SCHOPENHAUER, A. M, $§ 2$, p. 22.

${ }^{2}$ Cf. CARTWRIGHT, D. "Schopenhauer's Narrower Sense of Morality”, p. 255.

${ }^{3}$ Cf. ATWELL, J. Schopenhauer. The Human Character, p. 91.
} 
constante, entonces se vuelve baladí la tentativa de reformarlo mediante imperativos ${ }^{4}$. En su visión, la ética es impotente para producir una "buena voluntad". Por otra parte, la segunda razón por la cual se rechaza el prescriptivismo, es la siguiente: si bien aquél valora el esfuerzo de Kant por intentar vaciar la ética de toda consideración prudencial o egoísta, cree, asimismo, que al ser concebida como una disciplina prescriptiva, sólo puede hacer sentido como una forma de moral teológica, cosa que termina por reintroducir el egoísmo 5 .

En pocas palabras, Schopenhauer señala que nociones tales como las de "ley", “deber", “obligación”, son de procedencia extraña a la filosofía: el Decálogo de Moisés ${ }^{6}$; de manera que dichas nociones solamente se tornan significativas sobre la base de hipótesis teológicas. Separadas de ese contexto, pierden plausibilidad y sentido. Es digno de mención que idéntica observación fue indicada por GEM Anscombe en su influyente artículo de 1958 "Modern Moral Philosophy”. Allí hace la autora la misma apreciación que nuestro filósofo había efectuado ya, en su ensayo El fundamento de la moral. Hasta MacIntyre, en Tras la virtud, sigue esa pista señalada por Anscombe, y sobre ella modela las críticas que lanza, no sólo contra el kantismo, sino también contra la tradición moral moderna en su conjunto. Estas semejanzas evidencian en algún sentido, la filiación que pretendemos establecer entre Schopenhauer y la rehabilitación contemporánea de las éticas de la virtud.

Volviendo a la cuestión del prescriptivismo, nuestro filósofo lo rechaza porque considera que al hundir éste sus raíces en la teología, presupone necesariamente, so pena de carecer de sentido, de un legislador dispensador de premios y castigos. Siendo así, aquello que motivaría el cumplimiento del deber, no sería otra cosa que la perspectiva de la recompensa, del mismo modo que es el temor al castigo, lo que nos abstendría de incumplirlo. Si bien Schopenhauer reconoce que Kant procura en un principio deslindar nítidamente la motivación moral de la motivación prudencial, piensa que termina por concederle un lugar a esta última, ya que su prescriptivismo presupone, a riesgo de volverse ineficaz e ininteligible, el egoísmo del agente. En conexión con ello, el autor de El mundo como voluntad y representación sostiene que la idea de un "deber incondicionado", es implausible. Todo deber, si es que motiva, está condicionado (por los intereses del agente); y por tal razón, los imperativos no pueden nunca ser categóricos, sino simplemente hipotéticos ${ }^{7}$.

Sentados estos presupuestos, el filósofo de Danzig asevera que es preciso abandonar las viejas pretensiones de la filosofía moral: a saber, volverse práctica, guiar el comportamiento, remodelar el carácter. La ética, en tanto disciplina filosófica, es eminentemente teórica, por lo que su proceder ha de

\footnotetext{
${ }^{4}$ Cf. SCHOPENHAUER, A. MVR I, $\S 53$, pp. 365-366.

${ }^{5}$ Cf. ATWELL, op. cit., pp. 80-92.

${ }^{6}$ Cf. SCHOPENHAUER, A. M, $\S 4$, p. $31 ; 35$.

${ }^{7}$ Cf. SCHOPENHAUER, A. M, § 4, pp. 33-36; § 7, pp. 76-77.
} 
ser estrictamente descriptivo, antes que prescriptivo ${ }^{8}$. ¿Qué es aquello, entonces, a lo que queda reducida la teoría ética? A la descripción e interpretación de lo dado, esto es, el análisis de aquellos aspectos que permiten explicar las acciones virtuosas tanto como las viciosas. El mismo Schopenhauer afirma: "En oposición a Kant, yo digo que el moralista, como el filósofo en general, ha de conformarse con la explicación e interpretación de lo dado (...)"9. Como bien lo precisa MacIntyre, la filosofía moral, para aquél, se reduce a la tarea de explicar las valoraciones que efectuamos a través de un examen de la naturaleza humana ${ }^{10}$.

Hemos afirmado que el segundo aspecto que Schopenhauer encuentra recusable en la ética kantiana, es el relativo a su apriorismo. Con ello, se desean resaltar, al parecer, dos cosas: por un lado, que al postularse un soporte puro o priori para la moral, llega a identificarse la racionalidad con la moralidad, algo que nuestro autor considera inaceptable, ya que a su entender, el conocimiento general de los seres humanos, demuestra que "lo racional y lo vicioso son dos cosas que pueden ir muy bien unidas" "11; por el otro, que la ética de Kant, al carecer de contenido o materia, se vuelve, por carácter transitivo, inoperante. A este respecto, lo que Schopenhauer ambiciona señalar, es que puros preceptos a priori, son incapaces de poner en movimiento a criaturas como nosotros. $\mathrm{O}$ en otros términos: lo que se pone en tela de juicio, es la teoría de la motivación moral kantiana. Sentadas estas objeciones, el mismo llega a establecer que la ética ha de habérselas con la conducta real - wirklichen Handeln - de los seres humanos ${ }^{12}$. De manera opuesta a Kant, entonces, piensa que la misma debe fundarse en la antropología empírica, y considerar, en consecuencia, lo que de hecho son y hacen las personas, antes que aquello que deberían llegar a ser o hacer. En su óptica, el último fundamento de la moral, reside en la naturaleza humana ${ }^{13}$ :

De ahí que no haya más camino para el descubrimiento del fundamento de la ética que el empírico, es decir, estudiar si, en general, hay acciones a las que hemos de reconocer un verdadero valor moral, como serían los actos de justicia espontánea, de pura caridad y de verdadera nobleza de sentimientos. ${ }^{14}$

\section{El carácter y la virtud como objetos propios de las evaluaciones morales}

\footnotetext{
${ }^{8}$ Cf. SCHOPENHAUER, A. MVR I, $\S 53$, p. 365.

${ }^{9}$ SCHOPENHAUER, A. M, § 4, p. 29.

${ }^{10}$ Cf. MACINTYRE, A. Historia de la Ética, p. 215.

${ }^{11}$ SCHOPENHAUER, A. M, § 6, p. 67.

${ }^{12}$ Ibid., p. 59.

${ }^{13}$ Cf. Ibid., § 16, p. 144.

${ }^{14}$ Ibid., § 13, p. 126.
} 
Establecidas estas condiciones, el autor de El fundamento de la moral, señala a la ética la tarea de reconocer los móviles empíricos que llevan a las personas a actuar. Éstos, a su parecer, son tres: egoísmo (Egoismus), maldad (Bosheit) y compasión (Mitleid), quedando reservado solamente a esta última, valor moral. El egoísmo, en efecto, constituye el móvil principal de todas las criaturas -incluyendo a animales no-humanos-, y consiste en el deseo de vivir y de procurarse, incansablemente, bienestar. Este móvil puede engendrar acciones, o bien neutrales, o bien malas, desde el punto de vista moral. El último caso se presenta cuando, al buscarse el propio bienestar, otro resulta dañado. Es decir, el dolor infligido a los demás se convierte en medio para alcanzar el propio fin. Cuando, en cambio, su sufrimiento se vuelve directamente el móvil de la acción, estamos frente a la maldad, y no simplemente el egoísmo. Schopenhauer los diferencia de la siguiente forma: mientras el egoísta perjudica colateralmente a los otros, sin buscarlo directamente, el malvado lo tiene a la vista como un fin. La maldad es, por eso, el signo más patente de corrupción moral.

Ahora bien, una vez establecidas estas potencias anti-morales, Schopenhauer deduce de ellas los correspondientes vicios ${ }^{15}$. Del egoísmo, por ejemplo, se infieren los vicios de la injusticia, la codicia, la gula, el orgullo, la lujuria y la vanidad; mientras que de la maldad, los vicios de la envidia, la ira, la calumnia, el odio, la venganza, la traición y la alegría del mal ajeno -siendo este último el peor de los vicios-. Nietzsche recoge esta idea, y da cuenta de esta crueldad impotente, por su parte, en el tratado primero de La genealogía de la moral $^{16}$.

En contraste con estas potencias anti-morales, se reconocerá como exclusivo móvil moral a la compasión: se trata del fenómeno por el que se toma "participación directa, independiente de las demás consideraciones, primero en el dolor de otro y así en el impedimento o supresión de este dolor" ${ }^{\prime 17}$. La compasión, a su parecer, se trata de un hecho innegable de la conciencia humana, la cual:

(...) no se apoya en supuestos, conceptos, religiones, dogmas, mitos, educación y formación; sino que es originaria y directa, reposa en la misma naturaleza humana; por eso resiste bajo todas las condiciones, y se muestra en todos los países y en todos los tiempos; de ahí que (...) quien parece carecer de ella es llamado inhumano; igual que "humanidad" es, a menudo, sinónimo de compasión ${ }^{18}$.

Del incentivo de la compasión, se deducen, consiguientemente, las virtudes cardinales de la justicia (Gerechtigkeit) y la filantropía (Menschenliebe). De la primera, a su vez, se desprenden las virtudes de la honestidad, diligencia y equidad; de la segunda, las virtudes de la benevolencia, caridad y amor. La justicia exhibe en menor grado que la filantropía, la compasión, ya que obra negativamente,

\footnotetext{
${ }^{15}$ Cf. Ibid., § 14, pp. 131-134.

${ }^{16}$ Cf. NIETZSCHE, F. La Genealogía de la Moral, pp. 72-74.

${ }^{17}$ SCHOPENHAUER, A. M, § 16, p. 143.

${ }^{18}$ Ibid., § 17, p. 149.
} 
guardándose de provocar dolor; mientras que la filantropía es más perfecta, puesto que busca promover directamente el bien del otro, incitándonos en su ayuda.

Por lo visto hasta aquí, Schopenhauer localiza primero en la naturaleza humana los principales móviles de la acción. Una vez identificados, procede a la deducción de los correspondientes vicios y virtudes -mediante los cuales nos presenta una teoría unificada de unos y otros- ${ }^{19}$. El último paso, con todo, consistirá en la remisión de tales aspectos al carácter humano. El mismo es definido como "la constitución especial e individualmente determinada de la voluntad" ${ }^{20}$, mediante la cual ya están determinados, en esencia, los fines hacia los que invariablemente tiende ${ }^{21}$. El carácter, entonces, es innato e inalterable, de manera que ante la vieja cuestión de si la virtud deja enseñarse, Schopenhauer responde negativamente: las virtudes y los vicios son innatos ${ }^{22}$. Nuestro filósofo concede que los tres móviles fundamentales se presentan en cada carácter en una relación increíblemente diversa, y que estas diferencias explican la enorme variedad en la disposición moral de las personas, y ulteriormente, en su accionar ${ }^{23}$.

Con ello, Schopenhauer pretende defender dos importantes tesis: por un lado, que el carácter moral es innato, razón por la cual no admite ser modificado ni mejorado; por el otro, que el carácter, antes que las acciones, es el objeto de nuestras evaluaciones morales. Nos detendremos brevemente en este último punto, ya que, creemos, es el que concede actualidad a su planteo. Hemos referido con anterioridad que al anticipar muchas de las críticas que en el siglo XX se efectúan a la ética kantiana, es posible emparentarlo con la tentativa contemporánea de reavivar las éticas de la virtud. Pero ahora tenemos ante la vista una segunda razón por la que es posible establecer dicha filiación: Schopenhauer defiende un presupuesto medular para cualquier teoría enmarcada en aquellas últimas, esto es, que las evaluaciones morales no pueden desvincularse del análisis del carácter del agente. Como sostiene J. Atwell, en la óptica schopenhaueriana, el tópico general de la ética debe ser concebido, no tanto en términos de obediencia a reglas morales, ni de realización de cierto tipo de acciones, sino más bien, en términos de ser cierta clase de persona, o tener determinado tipo de carácter $^{24}$.

En la medida en que Schopenhauer pretende validar siempre empíricamente sus tesis, aduce que en nuestras evaluaciones morales ordinarias, no juzgamos precisamente, otra cosa que el carácter. Proporciona algunos ejemplos en dirección a ello: solemos retirar definitivamente nuestra confianza, a

\footnotetext{
${ }^{19}$ En opinión de Cartwright (1999: 269), Schopenhauer cuenta entre uno de los pocos filósofos en presentarnos una teoría unificada del vicio, algo descuidado tanto por los defensores clásicos como contemporáneos de las éticas de la virtud.

${ }^{20}$ SCHOPENHAUER, A. L, p. 138.

${ }^{21}$ Cf. Ibíd, p. 150.

${ }^{22}$ Cf. Ibid., p. 145.

${ }^{23}$ Cf. SCHOPENHAUER, A. M, § 20, p. 201.

${ }^{24}$ Cf. ATWELL, J. op. cit, p. 7.
} 
quien ha sido deshonesto con nosotros una única vez, porque presuponemos que esta acción procede de un carácter deshonesto, y que este rasgo es inalterable; si alguien, por otra parte, defrauda nuestras expectativas, jamás decimos: "su carácter ha cambiado", sino más bien, "me he equivocado con él o ella"25; de manera inversa, solemos mirar con confianza a quien ha dado una vez, muestra de nobleza, o acudir a quien ha dado una prueba de generosidad, pues le atribuimos tales rasgos como cualidades constantes de su carácter.

El filósofo alemán pretende, en definitiva, probar que las acciones de un agente se explican por su carácter, y no contrariamente; es así como llegamos a considerar fundamentalmente este último en nuestras apreciaciones morales. Elogiamos y encumbramos un tipo de carácter antes que de acción, del mismo modo que nuestra aversión y desprecio, no se dirigen tanto a la acción pasajera cuanto a las cualidades permanentes de su autor ${ }^{26}$. Además, nuestro filósofo conecta en forma interesante la cuestión de la felicidad (Glück) con la del buen carácter: el agente virtuoso no sólo experimenta contento consigo mismo por sus buenas acciones, sino que mediante ellas contribuye asimismo, y en forma principal, al bienestar ajeno.

De esta suerte, el carácter virtuoso, o lo que es lo mismo decir, la persona compasiva, al tomar participación directa en el dolor de otro, procurando evitarlo o suprimirlo, no hace más que auspiciar su felicidad ${ }^{27}$; pues esta última es definida por Schopenhauer en términos negativos, y así, en cuanto evitación o liberación de un dolor ${ }^{28}$. Por otra parte, éste señala una diferencia abismal entre la forma de consciencia y estado de ánimo del buen carácter respecto de la del malo, como en el siguiente pasaje:

El mundo es para [el malo] un no yo absoluto; y su relación con él es originariamente hostil: de ahí que el tono fundamental de su ánimo sea odio, desconfianza, envidia, alegría del mal ajeno. El buen carácter, en cambio, vive en un mundo exterior homogéneo con su ser: los otros no son para él ningún "no yo", sino "yo otra vez". De ahí que su relación originaria con cada uno sea amistosa: se siente en el interior emparentado con todos los seres; participa directamente en su felicidad y en su dolor, y supone confiado la misma participación en ellos. De aquí emana la profunda paz de su interior y ese estado de ánimo sereno, seguro, contento, gracias al cual se sienten bien todos los que están a su lado ${ }^{29}$.

Por lo antedicho, son dos las relaciones que pueden trazarse entre virtud y felicidad en la teoría moral schopenhaueriana. Por un lado, la persona virtuosa contribuye sustancialmente a la felicidad de los otros, en la medida en que su dolor no le resulta nunca indiferente, al procurar aliviarlo o suprimirlo por todos los medios. Dada la caracterización negativa de felicidad propuesta por

\footnotetext{
${ }^{25}$ Cf. SCHOPENHAUER, A. L, pp. 142-143.

${ }^{26}$ Cf. Ibid., p. 201.

${ }^{27}$ Cf. SCHOPENHAUER, A. M, p. 143.

${ }^{28}$ Cf. SCHOPENHAUER, A. MVR I, $\S 58$, pp. 415-416.

${ }^{29}$ SCHOPENHAUER, A. M, § 22, p. 225.
} 
Schopenhauer, decir que alguien evita o revoca un dolor a otro, o decir que promueve su felicidad, viene a significar lo mismo. Por el otro, se sugiere claramente, al igual que en las teorías eudemonistas antiguas, que la persona virtuosa experimenta en sí misma cierto equilibrio emocional, del que procede su serenidad y calma interior. Por contrapartida, el malvado es descrito por Schopenhauer en su obra principal, en términos de alguien sujeto a los más intensos sufrimientos, a raíz de la poderosa voluntad de vivir de la que es presa.

\section{Planteo de una objeción y de una posible respuesta}

Hemos tratado de verter esquemáticamente en este trabajo, algunas nociones de la ética schopenhaueriana que permiten situarla en una tradición ética en particular: la que hace del carácter y la virtud del agente, sus aspectos centrales, y que se remonta a Platón y Aristóteles. Con todo, una poderosa objeción puede ser planteada: ¿con qué derecho estamos autorizados a posicionar a Schopenhauer en dicha tradición de pensamiento, cuando sostiene un postulado que choca manifiestamente con una de las convicciones fundamentales de las éticas de la virtud? Nos referimos, en este caso, a la idea de que la virtud puede adquirirse, y por su intermedio, auspiciarse la eudaimonia. Por nombrar tan solo el punto de vista de su máximo representante, Aristóteles, "ninguna de las virtudes éticas se produce en nosotros por naturaleza", ya que las adquirimos como resultado de actividades anteriores $^{30}$. Esta concepción puede hacerse extensiva, aunque con ciertos ajustes, al resto de las éticas eudemonistas antiguas, puesto que parten de la idea según la cual, mediante la educación y el hábito, la virtud y la eudaimonia se vuelven asequibles a los seres racionales. En este sentido, J. Annas ha señalado que aquéllas comportan una visión optimista de la vida humana ${ }^{31}$. O tomemos aquí la caracterización que hace MacIntyre de la moral clásica. A su juicio, tres son los postulados sobre los que la misma se modela: 1) una concepción de naturaleza humana ineducada o tal-como-es; 2) una concepción de naturaleza humana tal-como-podría-ser si realizara su telos; 3) una concepción de los preceptos de una ética racional. De esta forma, la ética era concebida como la ciencia capaz de hacer pasar al ser humano del primer estado al segundo ${ }^{32}$; o en términos análogos, se creía en la posibilidad de su transformación y mejora.

Por lo visto anteriormente, Schopenhauer parece negar semejante posibilidad. Pues al postular que el carácter moral, y por ende la virtud, son innatos, la ética llegaría demasiado tarde con sus pretensiones reformadoras. De allí que, tal como deja sentado bien al comienzo del Libro IV de su obra

\footnotetext{
${ }^{30}$ ARISTÓTELES. Ética Nicomáquea 1103a 20-30.

${ }^{31}$ Cf. ANNAS, J. The Morality of Happiness, p. 46.

${ }^{32}$ Cf. MACINTYRE, A. Tras la virtud, p. 76.
} 
principal, la misma debe abandonar sus viejas aspiraciones de remodelar el carácter y guiar el comportamiento. Si esto es así, entonces se plantearía una diferencia tan aguda entre la perspectiva schopenhaueriana y aquella entrañada por las éticas de la virtud, que difícilmente podrían ser hermanadas. Sin embargo, ¿es realmente ésta la última palabra de Schopenhauer?; ¿en verdad piensa que la filosofía está por entero desprovista de su función práctica, y que es, por tanto, del todo impotente para transformarnos? Creemos que no, y por eso, sus tajantes palabras deben ser matizadas. Este problema es tan complejo, que un análisis satisfactorio demandaría cientos de páginas. Aquí nos contentaremos, no obstante, con ofrecer ciertas pistas o elementos, que a nuestro entender posibilitarían una "reconciliación" entre la filosofía moral schopenhaueriana y la óptica asumida por las éticas de la virtud. Para ello sugeriremos a continuación dos razones de peso para acercar ambas posiciones.

En primer lugar, la ética schopenhaueriana no parece responder a la pregunta por excelencia que la filosofía moral moderna se plantea, a saber: ¿qué debo hacer? El filósofo de Danzig no aparenta estar preocupado en ofrecer un criterio para guiar la acción de manera segura. En este sentido, su concepción de la teoría ética se aparta tanto del prescriptivismo kantiano como del utilitarismo, ambas concernidas con la dilucidación de un criterio firme que permita distinguir entre acciones no-morales de las propiamente morales, a fines de lograr encaminarnos en dirección a estas últimas. Si tenemos en cuenta el conjunto de los escritos morales de Schopenhauer, resulta plausible sostener, al menos en principio, que nunca estuvo concernido con semejante cuestión. En su lugar, parece estar interesado más bien en responder esta otra pregunta: “¿cómo debe uno vivir?”33. Es sabido que esta pregunta lanzada por Sócrates, unifica en buena medida la especulación ética antigua, ya que tanto Platón y Aristóteles, como asimismo también escépticos, estoicos y epicúreos, procuran ofrecer una respuesta.

Consideramos que la filosofía schopenhaueriana, sin forzar demasiado los términos, está animada por idéntico impulso. Sostener tal cosa puede resultar a primera vista problemático, ya que no encontramos esta afirmación de manera explícita entre sus escritos. Sin embargo, existen suficientes elementos como para presuponer que así lo pensaba. Ante todo, puede mencionarse como motivo de peso, el hecho de que nuestro autor, ya bien temprano, se preocupa por la filosofía en su vertiente práctica, esto es, por la cuestión de cómo vivir. Una vez reconocida nuestra esencia en cuanto voluntad, responsable en primer grado de nuestra condición desventurada, aquél comienza a delinear con ahínco, experiencias posibles en donde el dolor consustancial a la vida quede obliterado.

En la medida en que el placer y la felicidad son definidos negativamente, en cuanto ausencia de dolor, dichas experiencias son concebidas como ámbitos donde consigue rozarse una felicidad

\footnotetext{
${ }^{33}$ Cf. PLATON. La República $352 \mathrm{~d}$.
} 
verdadera. Las mismas son múltiples y variadas: abarcan, por un lado, la experiencia estética, donde según Schopenhauer se accede a ese estado exento de dolor en el que Epicuro veía el bien supremo; incluyen, por el otro, la experiencia ética propiamente dicha, en la que tanto la persona virtuosa como el asceta, traspasando el principium individuationis, alcanzan un estado de serenidad y calma que consigue ponerlos a resguardo del dolor; finalmente, tenemos la experiencia encarnada en la sabiduría mundana, por la que a través del conocimiento de sí y la prudencia, uno aprende a salvaguardarse del sufrimiento. Con arreglo a ello, y más allá de la peculiar forma en que nuestro filósofo defina a la felicidad, es innegable su esfuerzo por diseñar múltiples vías de escape a la natural condición del dolor. En otras palabras: creemos que su filosofía toda admite ser leída en clave eudemonológica, para utilizar su propia expresión. Así, la pregunta filosófica que parece desvelar a Schopenhauer es la de cómo vivir, de qué manera hacer frente al dolor, mediante qué instrumentos o artimañas armarnos frente al mismo. Tal como lo indica Cartwright, opinión que suscribimos enteramente aquí: aunque la pregunta “¿en qué consiste una buena vida?" emplee en último término un oxímoron, la fillosofía schopenhaueriana no es más que una lucha por responderla ${ }^{34}$.

¿Cuál es el segundo argumento por el que creemos posible situar a nuestro filósofo en la tradición ética de las virtudes? Hemos visto que la manera en que aquél concibe la virtud choca palmariamente con la concepción antigua, al atribuirle un carácter innato. Sin embargo, este supuesto contraste debe ser examinado más de cerca. La primera pregunta que debemos hacernos al respecto es si el autor de Parerga y Paralipomena entiende por "virtud" exactamente lo mismo que los antiguos. Nuevamente, dar una respuesta del todo satisfactoria exigiría un análisis mucho más pormenorizado, por lo que solamente podremos proporcionar aquí algunas pistas que permitan aproximarnos a una respuesta convincente. En dirección a ello, podría decirse que la concepción antigua de virtud es bastante más compleja que la del propio Schopenhauer, de modo que si uno comienza por establecer estas divergencias, luego dará con que diferencias más amplias concernientes a la función de la filosofía práctica y las posibilidades de transformación humana, no son tan grandes como a primera vista parecen. Para Schopenhauer, desde luego, la virtud está prioritaria y exclusivamente referida a cierta disposición o inclinación inscrita en la naturaleza humana, a la que se le da el nombre de compasión. De allí que la moralidad sea entendida como una cuestión de intencionalidad -Moralität der Gesinnung ${ }^{35}$-, y no tenga que ver tanto ni con las consecuencias de los actos ni tampoco con el proceso deliberativo mismo. Claramente, la concepción antigua de areté, abarca todas estas cuestiones, ya que la acción virtuosa, en su óptica, requiere tanto la recta disposición, como la correcta

\footnotetext{
${ }^{34}$ Cf. CARTWRIGHT, D. "Schopenhauer as Moral Philosopher", p. 57.

${ }^{35}$ Cf. SCHOPENHAUER, A. M, §14, p. 227 / Cf. también MVR I, § 62, p. 442.
} 
deliberación, y un resultado favorable. El problema, entonces, no es que Schopenhauer niegue semejantes cosas, sino que las excluya de su concepción de moralidad.

Lo que en su opinión no admite ser cambiado, es el carácter moral del agente, su disposición innata a la virtud o al vicio; pero tales disposiciones se constriñen únicamente a una cuestión de inclinación y sentimiento. Es tan solo este sentir, o este querer, lo que no puede cambiarse; pues Schopenhauer reconoce explícitamente, en contrapartida, que nuestro obrar o nuestra conducta sí admiten ser modificados a través de la persuasión, la educación y el conocimiento. ¿Y no conforma esto acaso uno de los postulados fundamentales de las éticas de la virtud, a saber, que mediante la instrucción y la guía de la razón práctica, podemos transformarnos y mejorar? A nuestro juicio, Schopenhauer sostiene una postura ambivalente con respecto a la razón práctica, puesto que en ocasiones le quita toda posibilidad de injerencia, pero en otras, se la concede sin ambages. Esta última perspectiva aparece sin dudas trazada en sus Aforismos $^{36}$, donde confiere un lugar importantísimo al uso de los preceptos abstractos de la razón para llevar una vida feliz.

Podría objetarse, con todo, en relación con lo anteriormente expuesto, que la óptica asumida en los Aforismos, tal como el mismo Schopenhauer lo establece, se sitúa por fuera de su punto de vista ético-metafísico más alto. Ya que allí intenta establecer un contraste bien marcado entre moralidad y prudencia. A su juicio, el uso de la razón práctica es siempre prudencial, mas nunca moral, al tener siempre en vistas la propia felicidad, un fin egoísta, y por tanto, exento de valor moral. Sin embargo, no queda en absoluto establecido firmemente, que la guía de la razón práctica carezca de relevancia moral, como lo sugiere este pasaje:

Pues aunque los principios y el conocimiento abstracto, en general, no son en modo alguno la fuente originaria, el fundamento de la moralidad, son, no obstante, imprescindibles para llevar una vida moral; son el depósito, el reservoir, en donde se guardan los sentimientos brotados de la fuente de toda moralidad (...) Saber mantenerse firme en estos principios y permanecer fiel a ellos, a pesar de todos los motivos contrarios, es dominarse a sí mismo ${ }^{37}$.

\footnotetext{
${ }^{36}$ Aunque sin dudas también, en el $§ 16$ de su obra principal, donde expone y discute ciertas tesis embanderadas por el estoicismo. En ese contexto, Schopenhauer parece evaluar positivamente a la razón práctica. De ello aparentan dar fe las siguientes palabras: "Tomada en su conjunto la ética estoica es, de hecho, un ensayo muy estimable y digno de atención por aplicar el gran privilegio del hombre, la razón, a un fin tan importante como saludable, cual es el de elevarle por encima de los sufrimientos y los dolores en que se halla inmersa la vida" (MVR I, §16, pp. 178-179) [El subrayado nos pertenece] Aunque Schopenhauer critica al estoicismo por su visión instrumental de la virtud, llega también a estimarlo, por su encumbramiento de la razón práctica. Hay al menos tres tesis que el filósofo alemán parece resaltar en su interpretación de esta escuela de la Antigüedad: 1) que la idea de razón práctica o prudentia, es desarrollada ejemplarmente por los estoicos; 2) que su ética no consiste sustancialmente en una doctrina de la virtud, como aparenta ser a primera vista, sino en una indicación para la vida racional; ya que 3) su objetivo último es alcanzar la dicha a través de la aplicación de la razón. En sus Aforismos, el mismo no presume sino desplegar idéntica idea, al postular la guía racional de las acciones como el medio más seguro para sustraerse de toda penalidad, y alcanzar así la felicidad - un estado exento de dolor equiparable a la paz interior-.

${ }^{37}$ SCHOPENHAUER, A. M, §17, p. 151. [El énfasis pertenece a Schopenhauer].
} 
Schopenhauer realiza semejante afirmación en el contexto de su análisis de la virtud de la justicia. Ésta se halla representada por la máxima "neminem laede". No es necesario -señala nuestro autor- que la compasión se despierte siempre espontáneamente en nosotros, ya que en ocasiones -agrega-, llega demasiado tarde. De allí la necesidad de un mandato de la razón, para llegar a la resolución firme de respetar el derecho de otro ${ }^{38}$. Con arreglo a ello, parece sugerirse que no podemos dejar simplemente en manos de la inclinación, que puede o no eventualmente surgir, la moralidad. Aún más: en el pasaje citado refiere la relevancia moral del autodominio mediante la razón, otras de las ideas medulares de las éticas antiguas.

Si los análisis efectuados hasta aquí se han realizado en la dirección correcta, entonces tenemos buenas razones para creer que su posición no se distancia abismalmente de las éticas de la virtud, por cuanto reconoce un rol importante a la razón práctica en la vida moral.

\section{A modo de cierre}

Hemos querido presentar en este trabajo, distintos componentes de la ética de Schopenhauer que hacen de ella un planteo actual, pudiendo contribuir al extensísimo debate que en las últimas décadas se ha generado en torno de las éticas de la virtud. Éstas, antes que concentrarse en los principios de la buena o la mala acción, tienden a interesarse por delinear comprehensivamente los contornos de la vida buena ${ }^{39}$. Las mismas, de las que las éticas antiguas constituyen un caso paradigmático, no presuponen como conceptos básicos aquellos de “obligación”, “deber”, o "seguir una regla"40. En su lugar, emplean nociones más "atractivas" como las de "bondad" o "valor", ya que sus intereses primarios se entretejen en derredor de las siguientes cuestiones: la formación del carácter y la práctica de las virtudes, el rol de las emociones y del razonamiento práctico, todo ello bajo el telos fundamental que impulsa la especulación ética antigua, a saber: el logro de la eudaimonia. Algunos filósofos contemporáneos encuentran en esta clase de teoría, por el tipo de cuestiones que característicamente aborda, una opción más rica y fructífera, razón por la cual vuelve a pensarse que es posible conectar la moralidad, en un importante sentido, con la visión que el agente tiene de su vida como un todo, con su virtud y felicidad. Si nuestras apreciaciones sobre la filosofía moral de

\footnotetext{
${ }^{38}$ Cf. Ibíd.

${ }^{39}$ Cf. STRIKER, G. "Greek Ethics and Moral Theory", p. 183.

${ }^{40}$ Cf. ANNAS, J. op. cit., p. 4.
} 
Schopenhauer son en esencia acertadas, entonces habría buenas razones para situarlo en esta rica tradición de pensamiento ${ }^{41}$.

\title{
Referencias
}

ANNAS, J. The Morality of Happiness. New York: Oxford University Press, 1993.

ATWELL, J. Schopenhauer. The Human Character. Philadelphia: Temple University Press, 1990.

ARISTÓTELES. Ética Nicomáquea. Madrid: Gredos. Traducción de Julio Pallí Bonet, 1993.

CARTWRIGHT, D. "Schopenhauer's Narrower Sense of Morality", In: JANAWAY, C. (ed) The Cambridge Companion to Schopenhauer. Cambridge: Cambridge University Press, pp. 252-292, 1999.

. "Schopenhauer as Moral Philosopher. Towards the actuality of his ethics", Schopenhauer-Jahrbuch 70, pp. 54-65, 1989.

MACINTYRE, A. Historia de la ética. Barcelona: Paidós, 1994.

. Tras la Virtud. Barcelona: Crítica, 2004.

NIETZSCHE, F. La Genealogía de la Moral. Buenos Aires: Alianza Editorial. Traducción de Andrés Sánchez Pascual, 2012.

PLATÓN. La República. Madrid: Alianza Editorial. Traducción de J.M. Pabón y M. Fernández-Galiano, 1988.

SCHOPENHAUER, A. El fundamento de la moral. Buenos Aires: Aguilar. Traducción de Vicente Romano García, 1960.

Romano García, 1960.

. Sobre el libre albedrío. Buenos Aires: Aguilar. Traducción de Vicente

\begin{abstract}
${ }^{41}$ Un capítulo aparte merecería la consideración del ascetismo y su relación con la virtud en la ética schopenhaueriana. Pues las ideas de renuncia y salvación -propiciadas por la negación de la voluntad de vivir- son nociones mayormente ajenas a las éticas antiguas. En este sentido - podría nuevamente objetarse-, la filosofía moral de Schopenhauer difícilmente pueda ser situada en dicha tradición de pensamiento, mostrando mayor afinidad, por cierto, con el budismo y la tradición moral cristiana. Si bien es cierto que el ideal griego de eudaimonia, no exigía en absoluto la renuncia al mundo, y en esto habría una diferencia sustantiva en relación con el contenido del bien supremo, creemos que desde el punto de vista formal y estructural, la teoría ética schopenhaueriana admite ser reconstruida en términos análogos a la de las antiguas. Esto es así por la sencilla razón de que reconoce un "bien supremo" -la ataraxía auspiciada por la negación de la voluntad- al que se le concede el rol principal en la teoría ética: pues es considerado, al igual que el ideal de eudaimonia para los griegos, como la mejor condición a la que un ser humano puede acceder. Asimismo, y al igual que en los sistemas antiguos, Schopenhauer tematiza la relación de las virtudes respecto del bien supremo. Esta cuestión aparece tratada en el §68 de su obra principal. De una manera por demás problemática, nuestro autor insinúa que las virtudes apuntan teleológicamente al bien supremo -encarnado por la vida ascética-. A nuestro parecer, semejante señalamiento lo acerca peligrosamente a una visión instrumental de la virtud, rasgo característico, como él mismo lo define, de toda doctrina eudemonista. Si las virtudes representan para Schopenhauer un medio para alcanzar el bien supremo, luego su posición se tiñe, paradójicamente, de eudemonismo. Si esto es así, entonces habría una razón más para acercar su emplazamiento al de las teorías eudemonistas antiguas, fundamentalmente a la epicúrea, por ostentar más claramente que otras, una concepción instrumental de la virtud.
\end{abstract}


Roberto Aramayo, 2005.

El mundo como voluntad y representación I. Madrid: FCE. Traducción de

STRIKER, G. "Greek Ethics and Moral Theory", en The Tanner Lectures on Human Values, Vol. 9. Salt Lake City: University of Utah Press, pp. 183-202, 1988.

Recebido: $15 / 11 / 12$

Received: $11 / 15 / 12$

Aprovado: 01/12/12

Approved: 12/01/12 